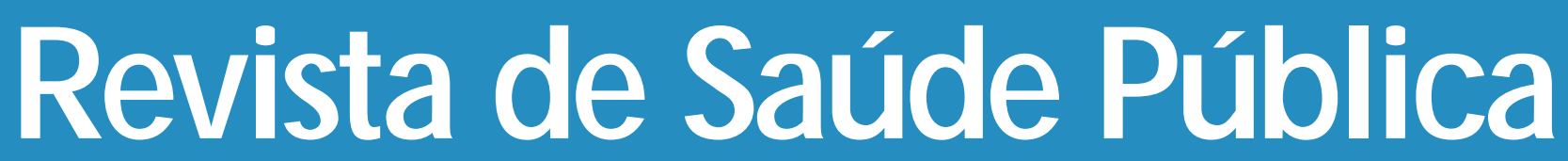

$\begin{array}{lllllll}J & \mathbf{O} & \mathbf{U} & \mathbf{R} & \mathbf{N} & \mathbf{A} & \mathbf{L}\end{array}$

0 F

$\begin{array}{llllll}P & U & B & L & I & C\end{array}$

H $\quad$ E $\quad A \quad L \quad T \quad H$

\title{
Características da mortalidade por acidentes de trânsito em localidade da região Sul do Brasil
}

\section{Characteristics of mortality in traffic accidents in an area of Southern Brazil}

Marlene Bonoto Scalassara, Regina Kazue Tanno de Souza e D orotéia Fátima Pelissari de Paula Soares

Centro de Ciências da Saúde da Universidade Estadual de Maringá. Maringá, PR - Brasil

SCALASSARA, Marlene Bonoto . Características da mortalidade por acidentes de trânsito em localidade da região Sul do Brasil, Rev. Saúde Pública, 32 (2): 125-32, 1998

(c) Copyright Faculdade de Saúde Pública da USP. Proibida a reprodução mesmo que parcial sem a devida autorização do Editor Cient́fico. Proibida a utilização de matérias para fins comerciais. All rights reserved. 


\title{
Características da mortalidade por acidentes de trânsito em localidade da região Sul do Brasil
}

\section{Characteristics of mortality in traffic accidents in an area of Southern Brazil}

\author{
Marlene Bonoto Scalassara, Regina Kazue Tanno de Souza e Dorotéia Fátima Pelissari de \\ Paula Soares \\ Centro de Ciências da Saúde da U niversidade Estadual de Maringá. Maringá, PR - Brasil
}

\begin{abstract}
Resumo
Objetivo

Discutir a situação da mortalidade por acidentes de trânsito a partir da caracterização das vítimas fatais.

Material e Método

Resultados e Conclusões

Objective

Material and Method

Results and Conclusions

A população de estudo foi constituída por 65 vítimas de acidentes de trânsito ocorridos, no Município de Maringá, Paraná (Brasil), em 1992, e que faleceram nesse mesmo ano.

Dos 65 óbitos, houve predominância de vítimas do sexo masculino, na faixa etária de 20 a 49 anos e que se encontravam na condição de pedestre (29\%), usuário de motocicleta ( $34 \%$, sendo $28 \%$ condutores e $6 \%$ passageiros) e ciclista $(18 \%)$. Os acidentes ocorreram, principalmente, no início da tarde e da noite e nos cruzamentos das avenidas de maior fluxo. Concluiu-se que mesmo em áreas urbanas do interior, as consequiências de acidentes de trânsito constituemse em um dos principais agravos à saúde da população e revelam um padrão de comportamento distinto a exigir também medidas específicas de prevenção.

Acidentes de trânsito, mortalidade.

\section{Abstracts}

The mortality by traffic accidents is discussed by means of the characterization of residents who died as a result of accidents in 1992.

The study population was made up of all the victims of accidents which occurred in 1992 and who died in the same year.

The majority of victims were males between the ages of 20 and 49 years who were pedestrians (29\%), motorcycle riders (34\%) or cyclists (18\%). The accidents occurred mostly in the early afternoon and evening at crossroads of the busiest avenues. It may be concluded that even in the interior towns the consequences of traffic accidents constitute one of the principal hazards to the population's health and reveal a distinct pattern that calls for measures specific prevention.
\end{abstract}

Accidents, traffic mortality. 


\section{INTRO DUÇÃO}

As mortes violentas na atualidade representam a segunda causa de mortalidade no Brasil e correspondem a aproximadamente $12 \%$ do total, inferior apenas a óbitos por doenças do aparelho circulatório (Rouquayrol e col. ${ }^{25}$, 1993; Barreto e Carmo $^{5}$, 1994). Mas, dependendo do grupo etário enfocado, assume a primeira posição. Conforme mostram vários estudos, a grande parte das mortes que incidem sobre o grupo etário de 15 a 29 anos é por causas externas ${ }^{17,18,20,31}$.

O problema das mortes violentas é destaque tanto nas sociedades desenvolvidas como nas subdesenvolvidas, sendo que os acidentes de trânsito respondem por importante parcela deste grupo de causas (Mesquita ${ }^{19}$, 1990; Ott e col. ${ }^{23}$, 1993; OPAS $^{21}$,1994). Esses merecem especial atenção porque, além de tantas mortes, determinam graus variados de incapacidade física em expressivo número de vítimas (Ott e col. ${ }^{23}, 1993$; OPAS ${ }^{21}$, 1994).

Scielsleski ${ }^{26,27}$ (1982) afirma que os acidentes de trânsito não são uma fatalidade, como boa parte da população insiste em acreditar, mas ocorrem pela deficiência na conservação de veículos e estradas ou, ainda, são provocados pelos pedestres e condutores e, as falhas humanas se sobrepõem aos demais determinantes dos acidentes. A ocorrência de um significativo número de acidentes de trânsito envolvendo vítimas fatais é freqüentemente associado a grandes centros urbanos como cidades de São Paulo e Rio de Janeiro (Minayo ${ }^{20}$, 1994) e às grandes rodovias. No entanto, as estatísticas oficiais vêm mostrando que a questão das mortes no trânsito é também destaque nas localidades do interior (Ipardes $^{8}$, 1991) e muitos ocorrem dentro do perímetro urbano. Na capital do Paraná, Curitiba, e em Londrina-PR (município com aproximadamente 500.000 habitantes) o trânsito é o maior responsável pelas vítimas da violência, afetando principalmente o grupo etário de 18 a 30 anos e o sexo masculino (Almeida², 1992; Andrade $\left.{ }^{3}, 1995\right)$. Situação semelhante é observada em Maringá-PR, local onde as estatísticas de mortalidade acusaram, em 1992, um coeficiente de mortalidade por acidentes de trânsito de 34,6 óbitos por 100.000 habitantes, valor esse superior ao observado para o País (20 por 100.000 hab.) e até mesmo para o Município de São Paulo (21,9 por 100.000 hab.) em 1992 (Mello Jorge e Latorre $\left.^{18}, 1994\right)$.

Pela relevância do tema, muitos estudos vêm sendo desenvolvidos no País, analisando principalmente as estatísticas oficiais (Klein ${ }^{9}, 1994$;
Mello Jorge e Latorre ${ }^{18}$, 1994). Apesar dessas estatísticas permitirem a caracterização das vítimas por sexo e faixa etária, apresentam falhas quando se pretende associar aos tipos de acidentes, pelos altos percentuais classificados como acidentes de trânsito de natureza não especificada ${ }^{18}$. No Município de Maringá, por exemplo, em 1992, nas tabulações especiais de mortalidade emitidas pelo Sistema Estadual de Informações sobre Mortalidade, 65,9\% dos óbitos por acidentes de trânsito foram codificados como de natureza não especificada.

O presente estudo tem por finalidade caracterizar as vítimas fatais de acidentes de trânsito ocorridos em uma localidade do Interior do Estado do Paraná segundo variáveis relativas aos acidentados, e analisar as circunstâncias em que ocorreram tais acidentes.

\section{MATERIAL E MÉTO DO}

A casuística foi composta por 65 vítimas fatais de acidentes de trânsito, ocorridos na área geográfica do Município de Maringá, e aí residentes, falecidas entre 1 de janeiro e 31 de dezembro de 1992. Para identificar as vítimas fatais foram consultadas as cópias das Declarações de Óbito (DO) arquivadas na Seção de Vigilância Epidemiológica da Secretaria Municipal de Saúde de Maringá e os Boletins de Ocorrência de Acidentes de Trânsito arquivados na Seção de Plantão de Acidentes do $4^{\circ}$ Batalhão da Polícia Militar de Maringá.

As variáveis de estudo foram: sexo, idade, causa básica de morte, qualidade da ação desenvolvida pela vítima no acidente, tipo de acidente, dia e local do acidente.

Os procedimentos adotados foram os seguintes:

- seleção de todas as DO cujas causas de morte mencionadas sugerissem acidentes de trânsito;

- confirmação dos casos identificados ou localização dos não identificados pelas DO, através da consulta aos Boletins de Ocorrência de Acidente de Trânsito de igual período;

- verificação de todos os registros referentes às vítimas de acidentes de trânsito no Livro de Registro do Instituto Médico Legal, visando a complementar informações ou elucidar as que se apresentavam conflitantes.

As informações coletadas foram transportadas para uma única planilha e avaliou-se caso a caso quanto à inclusão, ou não, no estudo. Além disso, por permanecerem algumas situações com informações conflitantes ou ausentes, utilizou-se também o Livro de Registro Civil do Cartório e prontuários hospitalares. A identificação dos prontuários partiu do entendimento que o dia e hora do acidente aproximam-se à internação. Nos casos em que restavam dúvidas, foram feitos contatos com familiares através de telefonemas e visitas domiciliares.

A seleção e codificação da causa básica de óbito foi realizada por uma técnica da Seção de Vigilância 
Epidemiológica, com base na Classificação Internacional de Doenças - CID-9, devidamente treinada.

Para cálculo de coeficientes utilizou-se dados do IX e X Recenseamentos Gerais do Brasil. Na composição do denominador estimou-se a população para primeiro de julho, do ano calendário em questão, através do método aritmético $^{12}$. No cálculo de coeficientes por grupo de idade, para conhecer-se a população, aplicou-se a proporção por faixa etária identificada no Censo de 1991, à população estimada para primeiro de julho de 1992.

\section{RESU LTAD O}

No ano de 1992, ocorreram no Município de Maringá 59 acidentes no trânsito, envolvendo vítimas fatais residentes no município, resultando em 65 mortes. Na investigação inicial haviam sido selecionadas 73 DO na Seção de Vigilância Epidemiológica, que, após verificação, foram excluídos 12 casos por não se enquadrarem nos critérios adotados.

Dos 61 casos foram acrescentados quatro óbitos (não localizados na Seção de Vigilância Epidemiológica) identificados através dos Boletins de Ocorrência de Acidentes de Trânsito, comprovados no IML e devidamente registrados no Cartório de Registro Civil, não constituindo portanto caso de sub-registro, mas relacionado à falha no sistema de arquivamento de cópias das DO na instituição.

Esclareceu-se que os dados oficiais revelaram, para o mesmo ano, 85 óbitos por esta causa, indicando a ocorrência da maioria dos óbitos na área geográfica do município e um coeficiente de mortalidade, em residentes, da 34,6 por 100.000 habitantes.

A evolução da mortalidade entre 1989 e 1993 e os valores apresentados na Tabela 1 indicam que a taxa referente ao ano de 1992 está discretamente abaixo dos anos anteriores e as mortes por essas causas vêm representando mais de $7 \%$ do total de óbitos. O coeficiente de mortalidade encontrado foi de 26,4 por 100.000 habitantes.

A grande maioria das vítimas estudadas $(95,4 \%)$ residia em área urbana. Verifica-se na Tabela 2 maior proporção de óbitos no sexo masculino para quase todas as idades (exceção para menores de 5 anos). Quanto às características das vítimas por sexo e faixa etária, apesar do maior peso relativo, entre os óbitos, da faixa etária de 20 a 49 anos, a população com mais de 64 anos é a mais exposta ao risco de morrer (Tabela 3).

A Figura 1 mostra a ação desenvolvida pela vítima no momento da ocorrência. A maior proporção de óbitos foi de pedestres, seguida pelos motociclistas e pelos ciclistas $(29,2 \%, 27,7 \%$ e $18,5 \%$, respectivamente), totalizando essas ações mais de

Tabela 1 - Coeficiente de mortalidade por acidentes de trânsito em residentes no Município de Maringá-PR, 1989-93.

Table 1 - Mortality rate resulting from traffic accidents involving city residents in Maringá, 1989-93.

\begin{tabular}{cccc}
\hline Ano & População* & Ó bito & Coeficiente por 100.000 habitantes \\
\hline 1989 & 226.100 & 96 & 42,5 \\
1990 & 232.650 & 116 & 49,9 \\
1991 & 239.200 & 92 & 38,5 \\
1992 & 245.751 & 85 & 34,6 \\
1993 & 252.301 & $91^{* *}$ & 36,1 \\
\hline
\end{tabular}

Fonte: Fundação IBG E7/Sistema Estadual de M ortalidade do Paraná

* População estimada para primeiro de julho, através do método aritmético.

**D ados preliminares

Tabela 2 - Ó bitos por acidentes de trânsito, em residentes, ocorridos no município segundo sexo e faixa etária. Maringá-PR, $1992\left(N^{\circ}\right.$ e \%).

Table 2 - Deaths resulting from traffic accidents involving town residents by sex and age. Maringá -PR, 1992 ( $N^{\circ}$ and \%).

\begin{tabular}{|c|c|c|c|c|c|c|}
\hline \multirow{3}{*}{ Faixa etária } & \multicolumn{4}{|c|}{ Sexo } & & \\
\hline & \multicolumn{2}{|c|}{ Masculino } & \multicolumn{2}{|c|}{ Feminino } & \multicolumn{2}{|c|}{ Total } \\
\hline & $\mathrm{N}^{0}$ & $\%$ & $\mathrm{~N}^{\circ}$ & $\%$ & $\mathrm{~N}^{\circ}$ & $\%$ \\
\hline 5 a 19 & 13 & 81,3 & 3 & 18,7 & 16 & 100,0 \\
\hline 20 a 49 & 27 & 81,8 & 6 & 18,2 & 33 & 100,0 \\
\hline 50 a 64 & 5 & 100,0 & - & - & 5 & 100,0 \\
\hline Total & 50 & 76,9 & 15 & 23,1 & 65 & 100,0 \\
\hline
\end{tabular}


$75 \%$ dos óbitos no trânsito.

Na Tabela 4 observa-se que quase $30 \%$ dos óbitos decorreram de atropelamentos, seguidos pelas colisões entre veículos automotores $(26,2 \%)$, mostrando que os tipos de acidentes diferem entre as faixas etárias. Enquanto que entre pessoas de 65

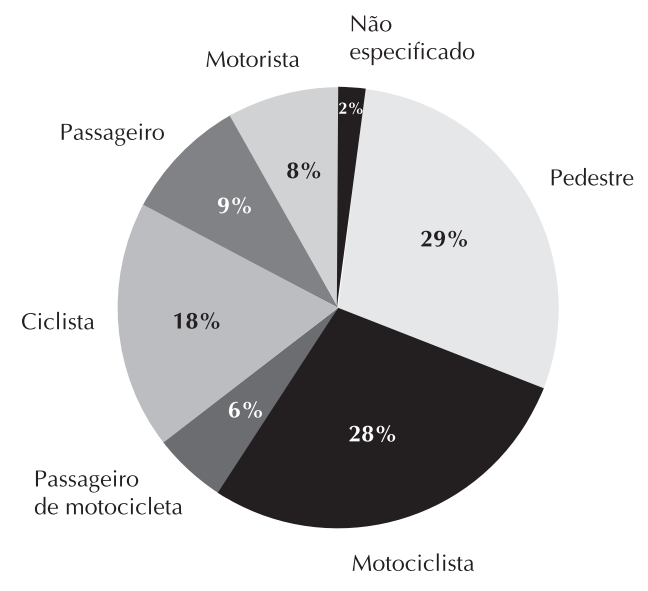

Figura 1 - Ó bitos por acidentes de trânsito em residentes segundo a qualidade da vítima. M aringá-PR, 1992.

Figure 1 - Deaths resulting from traffic accidents involving town residents according to the victim's category. Maringá - $P R, 1992$. anos e mais quase $90 \%$ dos óbitos foram consequientes a atropelamentos, na faixa etária imediatamente anterior (50 a 64 anos), dos 4 óbitos com tipo de ocorrência conhecida, 3 envolviam bicicletas e o outro foi por atropelamento. Entre $20 \mathrm{e}$ 49 anos, as colisões responderam por $54,5 \%$ dos óbitos e em menor proporção os acidentes envolvendo bicicletas $(21,2 \%)$ e os atropelamentos $(15,2 \%)$. No grupo etário de 5 a 19 anos tiveram a mesma importância os atropelamentos, as colisões entre veículos a motor, outras formas de colisão e colisão de veículo motor com bicicleta (com 25\% para cada tipo de ocorrência).

Relativamente aos acidentes, 83,1\% concentraram-se no perímetro urbano, em algumas avenidas de maior fluxo de veículos, com destaque à Avenida Colombo. Os cruzamentos constituíram-se em locais críticos das vias públicas e $25,4 \%$ dos acidentes ocorreram nesses locais.

A periculosidade por dia da semana foi notadamente mais elevada nos fins de semana $(54,8 \%$ dos acidentes fatais e 50,8\% dos óbitos), sendo que $23,7 \%$ dos acidentes concentraram-se no domingo, resultando em 29,3\% das mortes no trânsito (Figura 2). A Figura 3 mostra variação na ocorrência dos acidentes segundo o período do dia. O período da tar-

Tabela 3 - Coeficiente de mortalidade por acidentes de trânsito ocorridos no município, em residentes, segundo faixa etária. Maringá-PR, 1992.

Table 3 - Mortality rate in traffic accidents involving town residents by age. Maringá - PR, 1992.

\begin{tabular}{lrrrr}
\hline Faixa etária & População* & Ó bito & $\begin{array}{c}\text { Coeficiente por } \\
100.000 \text { habitantes }\end{array}$ & $\%$ \\
\hline 0 a 4 & 24.191 & 2 & 8,3 & 3,1 \\
5 a 19 & 71.831 & 16 & 22,4 & 24,6 \\
20 a 49 & 116.756 & 33 & 28,4 & 50,8 \\
50 a 64 & 22.956 & 5 & 21,9 & 7,7 \\
65 e mais & 10.861 & 9 & 82,2 & 13,8 \\
\hline Total & 246.842 & 65 & 26,4 & 100,0 \\
\hline
\end{tabular}

Fonte: Fundação IBGE ${ }^{7}$

* População estimada para primeiro de julho, através do método aritmético.

Tabela 4 - Ó bitos por acidentes de trânsito, em residentes, segundo tipo de acidente e faixa etária. Maringá-PR, $1992\left(N^{\circ}\right.$ e \%) Table 4 - Deaths resulting from traffic accidents involving the town residents by type of accident and age. M aringá - PR, 1992 $\left(N^{\circ}\right.$ and \%).

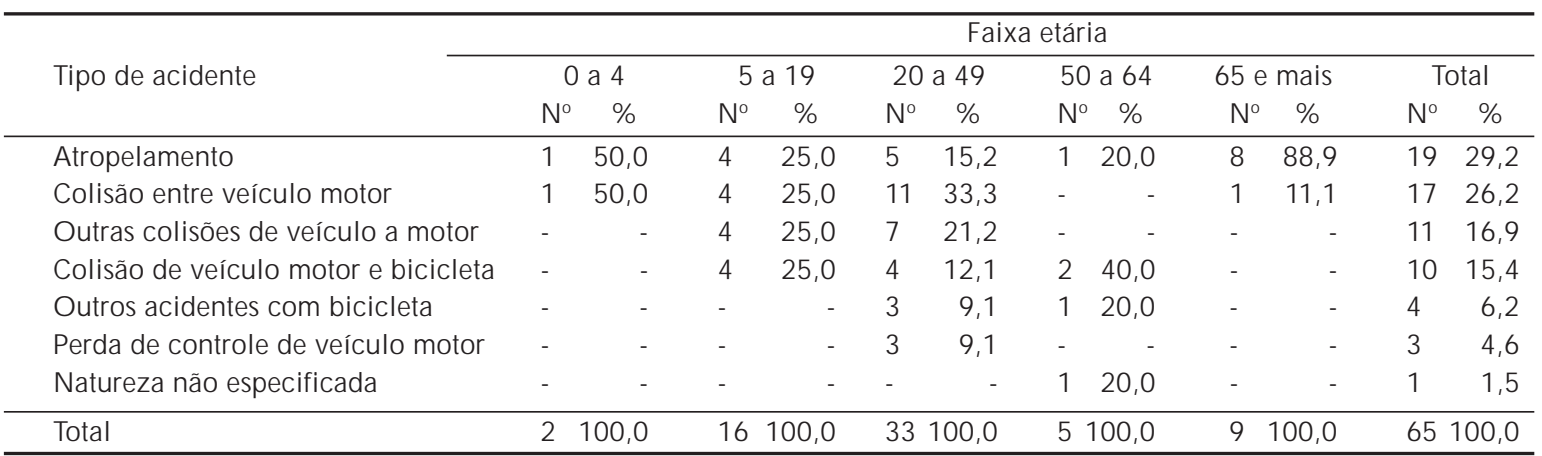


de e da noite foram marcados por maior proporção de acidentes com picos de ocorrência no início da tarde (entre 13 e 14 h) e início da noite (entre 18 e 19 h).

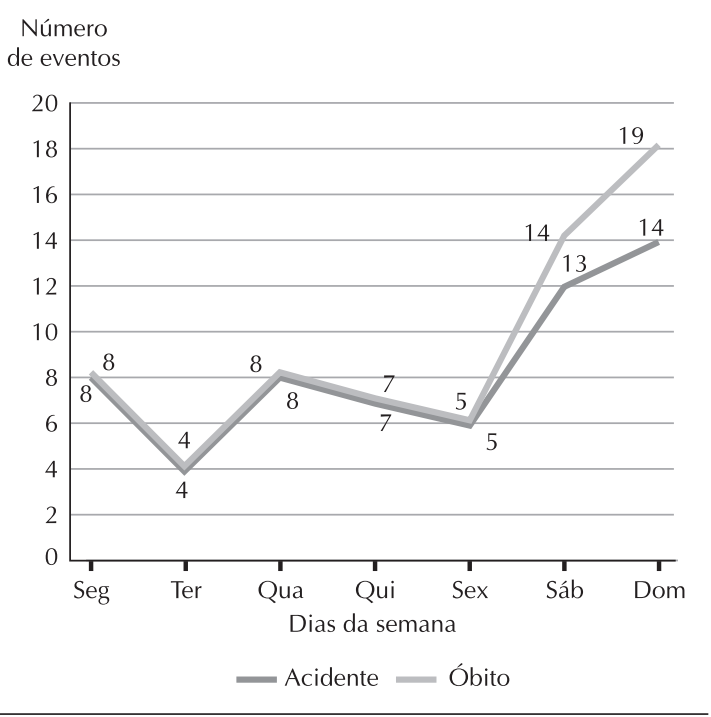

Figura 2 - Acidentes com vítimas fatais e óbitos por acidentes de trânsito, em residentes, segundo dia da semana. Maringá-PR, 1992.

Figure 2- Traffic accidents with fatal victims and number of deaths caused by traffic accidents, involving town residents, according to the days of the week. Maringá-PR, 1992.

Número

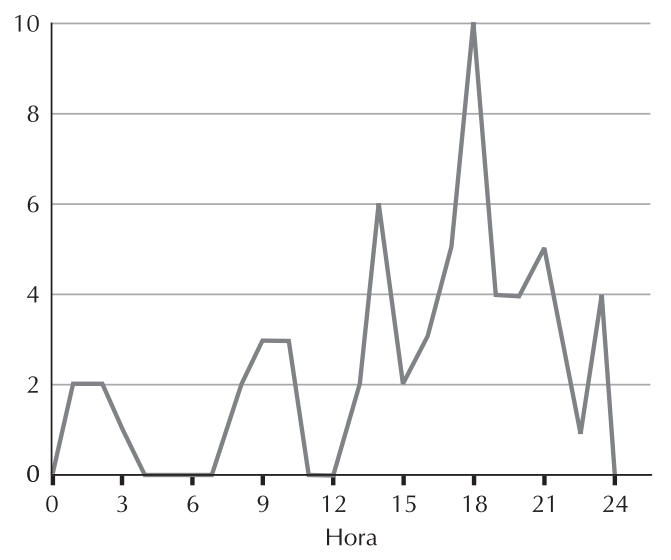

Figura 3- Acidentes de trânsito, com vítimas fatais residentes, segundo a hora de ocorrência. Maringá-PR, 1992.

Figure 3- Traffic accidents with fatal victims involving town residents according to the time of occurrence. Maringá- $P R$, 1992.

\section{DISCUSSÃO}

Os resultados encontrados para Maringá assemelham-se, na maioria das características, aos estudos desenvolvidos no País, em épocas recentes $\left(\right.$ Ott $^{23}$, 1993; Ribeiro ${ }^{24}$, 1994; Klein ${ }^{9}$, 1994; Ladeira ${ }^{11}$,
1995). Assim, as maiores taxas de mortalidade no sexo masculino e o maior peso dessas mortes em determinadas faixas etárias têm sido evidenciados em diferentes localidades (LLuis e col. ${ }^{13}$, 1987; Souza e Assis $^{29}$, 1990; Duarte ${ }^{11}$, 1993; Lucca e Mendes ${ }^{14}$, 1993). O coeficiente de mortalidade revelou maior exposição em indivíduos de 65 anos e mais, com razão entre coeficientes de 2,9 em relação à população de 20 a 49 anos. Esse achado fornece uma idéia do elevado risco de morte por essa causa entre os idosos, apesar de mais de $50 \%$ das vítimas fatais estudadas situarem-se na faixa etária de 20 a 49 anos evidenciando, também, o significado das mortes prematuras. Expressa bem tal significado o indicador de saúde Anos Potenciais de Vida Perdidos (APVP) (Laurenti e col. ${ }^{12}$, 1987). Soares ${ }^{28}$ (1996), ao discutir a importância dos acidentes de trânsito em Maringá, destaca que, em 1992, os valores mais altos assumidos por esse indicador referiram-se às mortes por acidentes de trânsito, superando até mesmo a mortalidade por doenças cerebrovasculares e homicídios (APVP de 2.463, 491 e 785 anos perdidos, respectivamente). A importância desse achado deveuse essencialmente à quantidade de mortes precoces, com destaque à faixa etária de 20 a 29 anos (enquanto que o valor do APVP assumido por todos os óbitos por acidentes de trânsito foi de 2.463 anos perdidos, entre 20 e 29 anos foi de 819 anos perdidos).

Quanto à explicação para o diferencial por sexo, observado para quase todas as faixas etárias, vários estudos relacionam à maior inserção do homem no mercado de trabalho, acarretando maior exposição em decorrência à atividade profissional e ao trajeto para o trabalho (Duarte ${ }^{6}, 1993$ ). Lucca e Mendes $^{14}$ (1993) constataram em pesquisa sobre acidentes de trabalho na região de Campinas-SP, entre 1981 e 1988, que cerca de $50 \%$ deles foram no trânsito. Embora presentes em todas as categorias profissionais, os acidentes incidiram predominantemente em profissões mais exercidas pelo sexo masculino, como condutor de veículos de transporte e seus ajudantes. Além desses fatores alguns autores atribuem também à maior exposição do homem aos fatores que atuam como coadjuvantes dos acidentes automobilísticos como consumo de álcool e comportamento mais agressivo do sexo masculino (Barchifontaine $^{4}$, 1992).

Ainda no tocante à maior exposição, determinadas ações desenvolvidas pelas vítimas, também em concordância com a literatura existente, conferem maior gravidade. Assim, apesar da questão dos passageiros de veículos de quatro rodas, em Maringá, parecer expressiva, a investigação mais amiúde des- 
ses casos possibilitou elucidar que um único acidente resultou em óbito de quatro passageiros de um mesmo automóvel, diferentemente de quase todos os outros eventos em que os óbitos foram conseqüentes a acidentes distintos. Tal fato demonstra a relevância da situação dos pedestres, usuários de motocicletas (condutores e passageiros) e de bicicletas, que representaram mais de $80 \%$ das mortes no trânsito, em Maringá. Especialistas na área afirmam que esses indivíduos são mais vulneráveis a riscos de traumas múltiplos, com destaque para os crânioencefálicos (Koizumi ${ }^{10}$, 1992; Ott e col. ${ }^{23}$, 1993). Em Maringá, verificou-se que $64,6 \%$ das injúrias sofridas pelos acidentados eram traumas crânioencefálicos e 7,7\% traumas raquimedulares.

Mello Jorge ${ }^{15,16}(1980,1982)$ há muito tem chamado atenção para o fato de ser conferida à condição de pedestre o maior risco de morrer em acidentes de trânsito na capital paulista e já apontava como determinantes da situação a falta de segurança e a falta de educação da população no trânsito (anos investigados 1960-75, 1980). Em anos recentes, os atropelamentos ainda têm sido destacados como o tipo de acidente que mais comumente tem levado à morte e à internação hospitalar (Ott e col. ${ }^{23}$, 1993; Mello Jorge e Latorre ${ }^{18}$, 1994). Na investigação realizada por Ott e col. ${ }^{23}$ (1993), em Porto Alegre, constatou-se que $50 \%$ das internações por acidentes de trânsito tratavam-se de atropelamentos.

No entanto, diferentemente do pedestre, em que fica evidente o tipo de acidente na classificação proposta pela Organização Mundial de Saúde (agrupamento referente aos acidentes de trânsito CID-9), no caso dos motociclistas e ciclistas o mesmo não ocorre, não possibilitando, pelas estatísticas de mortalidade, avaliar a magnitude dos acidentes envolvendo esses tipos de veículos. Em relação às motocicletas, em Maringá, 34\% dos óbitos envolveram usuários desse tipo de veículo seja como condutores $(28 \%)$ ou passageiros $(6 \%)$. Constatouse que $88,2 \%$ dos óbitos relativos às colisões entre veículos a motor e $36,4 \%$ de colisões de veículo a motor e objetos envolveram motocicletas. Estes veículos estavam envolvidos até mesmo em colisões com bicicletas (20\% das colisões de veículo motor e bicicleta). A importância das motocicletas nas mortes no trânsito de Maringá provavelmente guarda estreita relação com a quantidade desse veículo no Município. Segundo Divisão de Modernização Administrativa e Controle de Qualidade da Prefeitura de Maringá (1993), Maringá é a cidade do Paraná que apresenta maior valor para a relação número de motocicletas/população, superando, até mesmo, cidades como Londrina e Curitiba (5,14, 4,02 e 2,58 por 100 hab., respectivamente).

Embora não dispondo de dados, possivelmente a mesma situação seja observada para as bicicletas e a quantidade de usuários desse veículo também seja bastante elevada em Maringá, pois no presente estudo observou-se que o veículo a pedal envolveu-se em quase todos os tipos de acidente. Das 65 mortes estudadas, $15(23,1 \%)$ envolveram ciclistas em situações bastante adversas. A colisão entre veículo motor e bicicleta representou $15,4 \%$ (10 casos) do total dos falecimentos no trânsito local, sendo que nos 10 casos estudados 8 resultaram na morte de ciclistas e 2 de motociclistas. A participação dos veículos a pedal em acidentes fatais diz respeito a outras formas de acidentes como quedas e colisões com objetos inanimados (4 casos) ou, ainda, a uma morte por atropelamento ter sido ocasionada por bicicleta.

Porém, na casuística de Maringá é bastante provável que as situações de risco com uso de bicicletas envolvam trabalhadores que utilizam a bicicleta como meio de transporte, pois não houve ne-nhum acidente fatal, desta natureza, em menores de 15 anos e a maioria dos acidentes ocorreu em dias úteis (14 dos 15 acidentes deram-se de segunda à sábado).

No grupo etário de 50 a 64 anos, dos 5 óbitos ocorridos, 3 vítimas eram condutores de bicicleta. A vulnerabilidade desse grupo etário aos acidentes de bicicleta pode estar relacionada às deficiências físicas próprias da idade, mas $\mathrm{Acosta}^{1}$ (1988) aponta que a violação às normas de trânsito, por parte dos ciclistas, constitui fator coadjuvante na mortalidade por acidentes.

Mello Jorge ${ }^{15}$ (1980) faz referência a um baixo índice de mortalidade por acidentes de bicicleta. Salienta, a autora, que esse índice está associado ao hábito de utilização desse tipo de transporte que entre os paulistanos é pouco freqüente. Esta evidência é contrária à observada em Maringá, onde a bicicleta é um importante meio de transporte. Maringá é uma cidade cuja topografia plana, com projeto urbanístico que contempla largas avenidas, incentiva a utilização das bicicletas, representando uma alternativa econômica de transporte para o operariado do município. A título de ilustração, a exclusão das 15 mortes, envolvendo bicicletas, poderia significar a redução de $23,1 \%$ na ocorrência, dentro do município, de mortes de residentes no trânsito.

Entretanto, a expressão da violência no trânsito certamente seria melhor retratada se fossem incluídas no estudo todas as ocorrências, independentemente do município de residência da vítima, fato este que 
não constituiu objeto de análise do presente estudo. Há que se considerar que Maringá é município pólo com intenso deslocamento diário de um contingente de trabalhadores que, apesar de trabalhar em Maringá, reside em municípios circunvizinhos como Paiçandu e Sarandi, cuja proximidade torna possível o uso também de bicicletas como meio de transporte. Associada a esta questão, o fato da bicicleta constituir-se em uma alternativa econômica de trans-porte e os municípios de Sarandi e Paiçandu apresen-tarem indicadores sociais, econômicos e de saúde bastante inferiores ao de Maringá (Ipardes ${ }^{8}$, 1991; Souza ${ }^{30}$, 1992; Organ ${ }^{22}$,1996) são sugestivos desta prática.

Provavelmente este deslocamento de trabalhadores de, ou para, cidades próximas fazem da Avenida Colombo, que cruza a cidade e serve de corredor para as rodovias de alto fluxo que ligam por exemplo São Paulo a Foz do Iguaçu, um dos pontos críticos de Maringá, onde foram registrados $18,1 \%$ dos acidentes envolvendo vítimas fatais. Em muitas localidades do Paraná, rodovias que ligam as principais metrópoles do Estado cruzam a cidade e este fato tem sido apontada pelo Instituto de Desenvolvimento Social (Ipardes ${ }^{8}, 1991$ ) como um dos fatores responsáveis pelo incremento das taxas de mortalidade no trânsito.

Corroboram, ainda, a possibilidade de muitos acidentes envolverem trabalhadores e a ocorrência de maior número de acidentes no início da tarde e da noite em Maringá.

Além disso, seria interessante analisar a possível relação entre tipo de acidente e horário/dia da semana tendo em vista a ocorrência de maior número de acidentes em finais de semana. Porém, no presente estudo, o número de casos analisados não recomenda tal estratificação. Os maiores índices em finais de semana com uma distribuição mais regular ao longo dos demais dias não é especificidade do trânsito de Maringá e são relacionados a menor policiamento, a maior número de motoristas inexperientes e provável associação entre ingestão de bebida alcoólica e volante (Mello Jorge ${ }^{15}$, 1980). Tal fato pode também explicar a situação de Maringá, pois observou-se que dos motoristas envolvidos em acidentes 4 eram menores de 18 anos e 5 não possuíam habilitação.

Assim, os resultados relativos à Maringá reafirmam achados de outros estudos e acrescentam novos elementos na compreensão das estatísticas que fazem do País uma referência de altas taxas de mortalidade por acidentes de trânsito e vão ao encontro de questões colocadas por Mello Jorge e Latorre ${ }^{18}$ (1994) para as quais, frente aos indicadores apresentados, qualquer estudo sobre a problemática do trânsito é justificável.

\section{CONSIDERAÇÕ ES FINAIS}

O estudo realizado mostra que mesmo em áreas urbanas do interior, onde a expressão da violência é menor comparativamente aos grandes centros urbanos, as conseqüências de acidentes de trânsito constituem-se um dos principais agravos à saúde da localidade. Os resultados obtidos, bem como, algumas questões levantadas na discussão dos resultados sugerem a necessidade de aprofundar o estudo acerca da violência no trânsito de Maringá. Neste sentido alguns apontamentos fazem-se necessários.

Um primeiro aspecto refere-se à fonte de informações freqüentemente utilizada para o monitoramento da situação. Os procedimentos adotados para a obtenção das informações relativas às variáveis de estudo demonstraram a dificuldade de analisar resultados com base em única fonte de dados. As DO mostraram-se pouco sensíveis para revelar a magnitude de determinados tipos de acidentes por apresentar uma importante parcela classificada como de natureza não especificada. Dada a importância deste sistema de informação, tal constatação reitera a necessidade de implementar medidas voltadas para melhoria da qualidade das informações relativas às DO, tais como, contatos intersetoriais dos serviços de Vigilância Epidemiológica do Município com Departamento de Trânsito e Instituto Médico Legal.

Um segundo aspecto refere-se à necessidade de prosseguir no estudo no sentido de responder às indagações, cujas respostas não foram de alcance deste estudo por não constituir objeto de trabalho. A melhor aproximação à realidade da violência no trânsito deverá ser buscada também na análise de todas ocorrências do município, incluindo vítimas não fatais e/ou não residentes.

A importância das bicicletas e das motocicletas nas mortes no trânsito de Maringá é indicativo de um padrão de comportamento, provavelmente, comum às várias cidades do interior, com topografias planas e predomínio de dias ensolarados com temperaturas acima de $20^{\circ} \mathrm{C}$, para as quais estes tipos de veículos constituem-se aos determinados grupos sociais e categorias profissionais, em uma alternativa econômica de transporte. Tais peculiaridades recomendam a observação de aspectos específicos na implementação das medidas tradicionalmente colocadas e passa até mesmo pela necessidade de incluir, em alguns projetos urbanísticos, a construção de ciclovias. 


\section{AGRADECIMENTOS}

À Professora Sabina Léa Davidson Gotlieb da Faculdade de Saúde Pública da USP pelas sugestões

\section{REFERÊNCIAS}

1. ACOSTA, O.B. Analisis de uma de las primeiras causas de muerte. Rev. Cubana Hig. Epidemiol., 26:3-16, 1988.

2. ALMEIDA, R. SIATE S.O.S do primeiro mundo. Divulg. Saúde Debate, 8:72-4, 1992.

3. ANDRADE, S.M. Acidentes de trânsito em Londrina-PR 1996. São Paulo, 1995. [Projeto de tese apresentado em Exame de Qualificação - Faculdade de Saúde Pública da USP].

4. BARCHIFONTAINE, C. Alcoolismo. Hosp. Adm. Saúde, 16(1): 37-70, 1992

5. BARRETO, M.L. \& CARMO, E.H. Situação de saúde da população brasileira: tendências históricas, determinantes e implicações para as políticas de saúde. Inf. Epidemiol. SUS, 3(3/4):7-33, 1994.

6. DUARTE, C.M.R. Perfil de mortalidade no Município do Rio de Janeiro. Saúde em Debate, (40):60-7, 1993.

7. FUNDAÇÃO IBGE. Censo demográfico do Paraná. Rio de Janeiro, 1994. (10 Recenseamento Geral do Brasil, 1991).

8. INSTITUTO PARANAENSE DE DESENVOLVIMENTO ECONÔMICO E SOCIAL, FUNDAÇÃO EDSON VIEIRA. Serviços públicos e política de saúde: mortalidade no Paraná. Curitiba, 1991.

9. KLEIN, C. Mortes no trânsito do Rio de Janeiro, Brasil. Cad. Saúde Pública, 10 (supl. 1): 168-76,1994.

10. KOIZUMI, M.S. Padrão das lesões nas vítimas de acidentes de motocicleta. Rev. Saúde Pública, 26: 306-15, 1992.

11. LADEIRA, R.M. Morbimortalidade por acidentes de trânsito em cinco hospitais de Belo Horizonte e Contagem, 1994/95. Belo Horizonte, 1995. [Dissertação de Mestrado Universidade Federal de Minas Gerais].

12. LAURENTI, R. et al. Estatísticas de saúde. São Paulo, EPU, 1987.

13. LLUIS, N.M. et al. Mortalidade por acidentes. algunos datos sobre comportamento em Cuba. Rev. Cubana Adm. Salud, 13:479-87, 1987

14. LUCCA, S. M. \& MENDES, R. Epidemiologia dos acidentes de trabalho fatais em área metropolitana da região sudeste do Brasil, 1979-89. Rev. Saúde Pública, 27:168-76, 1993.

15. MELLO JORGE, M.H.P. Mortalidade por causas violentas no Município de São Paulo. II - Mortes acidentais. Rev. Saúde Pública, 14:475-508, 1980.

16. MELLO JORGE, M.H.P. Mortalidade por causas violentas no Município de São Paulo. IV - A situação em 1980. Rev e à Enfermeira Udelysses Janete Veltrine Fonzar da Secretaria Municipal de Saúde de Maringá pela seleção e codificação da causa de óbito.

17. MELLO JORGE, M.H.P. Situação atual das estatísticas oficiais relativas à mortalidade por causas externas. Rev. Saúde Pública, 24:217-23, 1990.

18. MELLO JORGE, M.H.P. \& LATORRE, M.R.D.O. Acidentes de trânsito no Brasil: dados e tendências. Cad. Saúde Pública, 10(supl.1): 19-44,1994.

19. MESQUITA, C. Regiões metropolitanas: violência na vida e na morte. Dados, 14:1-14, 1990.

20. MINAYO, M.C.S. A violência social sob a perspectiva da saúde pública. Cad. Saúde Pública, 10(supl.):7-18,1994.

21. ORGANIZACIÓN PANAMERICANA DE LA SALUD. Mortalidad por acidentes y violencia en las Americas. Bol. Epidemiol., 15(2):1-8, 1994.

22. ORGAN, W. Mortalidade perinatal nos Municípios de Maringá, Paiçandu e Sarandi. Londrina, 1996. [Dissertação de Mestrado - Universiddade Estadual de Londrina].

23. OTT, E. et al. Acidentes de trânsito em área metropolitana da região Sul do Brasil: caracterização da vítima e das lesões. Rev. Saúde Pública, 27:350-6, 1993.

24. RIBEIRO, C.R. Acidentes de trânsito em Curitiba, um estudo epidemiológico. Curitiba, 1994. (Relatório de pesquisa do Sistema Integrado de Atendimento à Emergência).

25. ROUQUAYROL, M.Z. et al. Principais causas de morte no Brasil, 1979-1988. Inf. Epidemiol. do SUS, 2(5):28-37,1993.

26. SCIESLESKI, A.J. Aspectos psicopatológicos do homem no trânsito. Rev. Bras. Med. Tráf., 1(1):, 1982.

27. SCIESLESKI, A.J. Epilepsia e medicina do tráfego. Rev Bras. Med. Tráfego, 1(1): 1982.

28. SOARES, D.F.P.P. Vítimas de acidentes de trânsito em Maringá-PR, em 1995. Londrina, 1996. [Projeto de dissertação de Mestrado apresentado em Exame de Qualificação - Universidade Estadual de Londrina].

29. SOUZA, E.R. \& ASSIS, S.G. A questão da violência e saúde na América Latina. Saúde em Debate, 29:75-6, 1990.

30. SOUZA, R.K.T. Mortalidade infantil e sub-registro de nascidos vivos no Município de Maringá- PR, em 1989. São Paulo, 1992. [Dissertação de Mestrado - Faculdade de Saúde Pública da USP].

31. YUNES, J. \& RAJS, D. Tendencia de la mortalidad por causas violentas en la población general y entre los adolescentes de la región de las Américas. Cad. Saúde Pública, 10(supl. 1):88-125, 1994. 